\title{
Ultrasound enhanced thrombolysis in experimental retinal vein occlusion in the rabbit
}

\author{
Jörgen Larsson, Jonas Carlson, S Bertil Olsson
}

\begin{abstract}
Aims-To investigate if it was possible to lower the dose of streptokinase and maintain an effective thrombolysis by adding pulsed low energy ultrasound.

Methods-53 retinal veins in 27 rabbits were occluded by rose bengal enhanced laser treatment. Six rabbits were treated with streptokinase (50 $000 \mathrm{IU} / \mathrm{kg}), 10 \mathrm{rab}-$ bits were treated with a low dose of streptokinase (25 $000 \mathrm{IU} / \mathrm{kg})$, and 11 rabbits were treated with a low dose of streptokinase (25 $000 \mathrm{IU} / \mathrm{kg}$ ) and pulsed ultrasound during 1 hour. Fluorescein angiography was performed immediately before the thrombolytic treatment and after 12 hours.

Results-In the group treated with streptokinase $(50000 \mathrm{IU} / \mathrm{kg})$ all vessels were open. In the group that was given streptokinase (25 $000 \mathrm{IU} / \mathrm{kg}), 21 \%$ of the vessels were open. In the group that was treated with streptokinase (25 000 IU/kg) and ultrasound, $64 \%$ of the vessels were open. The difference between groups 2 and 3 is statistically significant $(p=0.011)$

Conclusion-Adding pulsed low energy ultrasound makes it possible to lower the dose of streptokinase while maintaining a good thrombolytic effect.

(Br F Ophthalmol 1998;82:1438-1440)
\end{abstract}

Retinal vein occlusion is the second most common vascular disease in the human eye. The most severe form of retinal vein occlusion is central retinal vein occlusion (CRVO). There are two forms of CRVO, the ischaemic and the non-ischaemic, both leading to loss of visual acuity. About $20-30 \%$ of the CRVOs are ischaemic and the majority of them develop secondary glaucoma and rubeosis. ${ }^{1}$ Many different treatments have been tried such as haemodilution, ${ }^{2-8}$ thrombolytic treatment, ${ }^{9-12}$ formation of chorioretinal anastomoses, ${ }^{13}$ and different drugs ${ }^{14}{ }^{15}$ that influence the microcirculation. For different reasons, none of these treatments is widely used today, either because of severe side effects or they are considered to be too complicated, such as haemodilution.

Thrombolytic treatment, with streptokinase and tissue plasminogen activator, is one of the most promising methods of treating a thrombus in the eye since it dissolves the clot, allowing the circulation to be re-established within a few hours. The side effects of thrombolytic treatment are haemorrhages and are a great problem. The incidence of severe haemorrhage when giving streptokinase to treat a myocardial infarction is around $0.5-1.0 \% .{ }^{16}{ }^{17}$ In a disease such as myocardial infarction, which is life threatening, this incidence of haemorrhage is acceptable, but in a patient with a retinal vein occlusion it is hard to accept life threatening side effects.

Dye enhanced photothrombosis is a method where a dye that absorbs maximally at a specific wavelength is injected intravenously immediately before laser treatment in order to enhance the absorption of the laser light and thus making it possible to use less laser energy. This method easily produces thrombi in the vessels. ${ }^{18-20}$

Based on earlier in vitro experiences ${ }^{21} 22$ we wanted to investigate whether it was possible to lower the dose of streptokinase by adding pulsed low energy ultrasound towards a thrombus in the eye. We investigated this in a model of experimental retinal vein occlusion in the rabbit eye.

\section{Methods}

Twenty seven albino New Zealand rabbits were used (27 eyes, 53 vessels), each weighing 3-3.5 $\mathrm{kg}$. The rabbits were anaesthetised with a mixture of Ketalar and Rompun. Their pupils were dilated with $1 \%$ cyclopentolate eyedrops. The animals were treated according to the guidelines and requirements of the government committee on animal experimentation ethics of the University of Lund and the ARVO convention for animal experimentation ethics.

Occlusion of the retinal veins was performed by dye enhanced photothrombosis. We used the same method to induce thrombi in the retinal veins as has been described previously by Oncel et al..$^{23}$ Rose bengal solution, $50 \mathrm{mg} / \mathrm{kg}$ (50 $\mathrm{mg} / \mathrm{ml}$ in sterile water), was injected in an ear vein immediately before the laser treatment. Argon green laser treatments were performed with a power of $0.14 \mathrm{~mW}$, a spot size of $100 \mu \mathrm{m}$, and a duration of 0.3 seconds. Each vessel was treated at a distance of a half to one disc diameter from the optic disc, until the blood flow was completely stopped in the vein. About 5-20 laser effects were needed for each vessel.

The rabbits were randomised into three groups-group 1 (six rabbits, six eyes, 12 vessels) was treated with an infusion in an ear vein of $50000 \mathrm{IU} / \mathrm{kg}$ streptokinase for 1 hour; group 2 (10 rabbits, 10 eyes, 19 vessels) was treated with an infusion in an ear vein of $25000 \mathrm{IU} / \mathrm{kg}$ streptokinase for 1 hour; group 3 (11 rabbits, 11 eyes, 22 vessels) was treated with an infusion in an ear vein of $25000 \mathrm{IU} / \mathrm{kg}$ streptokinase for 1 hour and was simultaneously given pulsed ultrasound directed towards the occluded vessels. 
FLUORESCEIN ANGIOGRAPHY

Thirty minutes after the laser treatment, fluorescein angiography was performed in order to confirm that the vessels were completely occluded. Sodium fluorescein at a concentration of $25 \%(250 \mathrm{mg} / \mathrm{ml}$ in sterile water) was injected in the ear vein. Fluorescein angiography was performed using the scanning laser ophthalmoscope (Rodenstock, Heidelberg, Germany). Vessels that were only partially occluded were excluded from the study. Twelve hours after the treatment, fluorescein angiography was performed again and the patency of the vessels was evaluated. The evaluation of the patency was performed by two of the authors (JL and JC) in a masked mode. All the pictures used for the evaluation were take 20-30 seconds after the injection of fluorescein.

ULTRASOUND EXPOSURE

Unfocused piezoelectric transducers (Ceram $\mathrm{AB}$, Lund, Sweden) with a resonance frequency of $1.0 \mathrm{MHz}$ and diameter of $20 \mathrm{~mm}$ were used. The transducers were excited by an electronic system consisting of a function generator (HP 3314A, Hewlett-Packard, Washington, USA) and a RF power amplifier (ENI 240L, ENI, Rochester, New York, USA). The output of the function generator was manually set to produce the desired ultrasound characteristics, as described below.

The transducers were calibrated by measuring the total radiation pressure on an ultrasound absorbing material (Ceram $\mathrm{AB}$ ), using an electronic balance (Precisa 400M, PAG Oerlikon AG, Zurich, Switzerland). In the experiment series, up to three transducers were coupled in parallel. Therefore, measurements were made to verify that the ultrasound output was the same regardless of the number of transducers coupled to the amplifier.

To allow good acoustic coupling between the transducer and the eye, ultrasound transmission gel was used (Aquasonic 100, Parker Laboratories Inc, NJ, USA). Owing to interference phenomena, the ultrasound beam is not uniformly distributed close to the surface of the transducer. To avoid this affecting the experiment, the ultrasound transmission gel was put between the cornea and the transducer. The distance was typically $10 \mathrm{~mm}$ between the transducer and the cornea, giving a total distance between the transducer and the vessel of about $25 \mathrm{~mm}$.

Pulsed ultrasound of $1 \mathrm{MHz}$ frequency was used: 100 pulses of $1 \mathrm{~W} / \mathrm{cm}^{2}$ was sent every millisecond (10\% duty cycle), resulting in a spatial average, temporal average intensity of $0.1 \mathrm{~W} / \mathrm{cm}^{2}$.

Pulsed low energy ultrasound was given during the same period of time that streptokinase was administered - that is, for 1 hour.

The rabbits were killed immediately after the second fluorescein angiography by an intravenous injection of pentobarbitone.

\section{Results}

The patency of the vessels was evaluated 12 hours after the laser treatment with fluorescein angiography. Vessels that were only partially
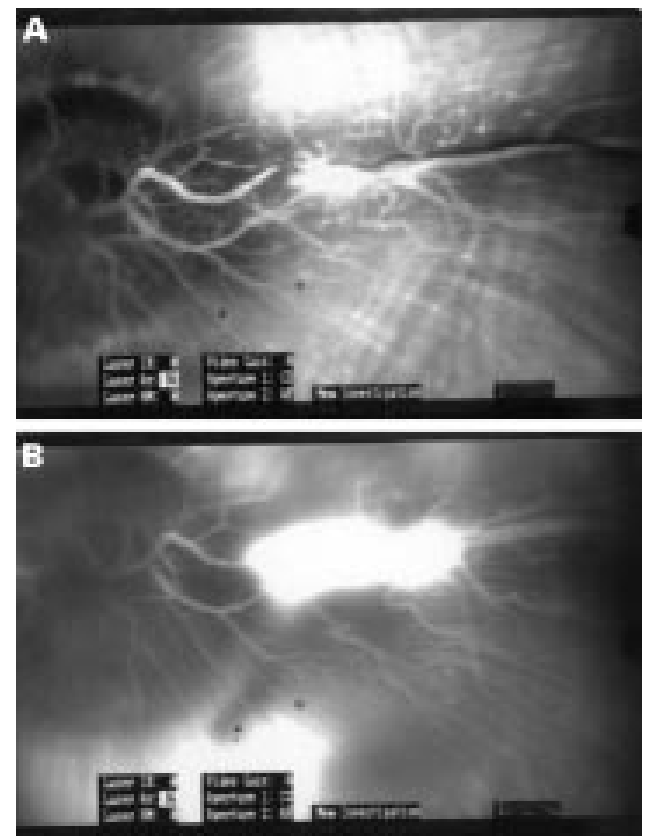

Figure 1 Theses fluorescein angiograms show an eye from group 3 that had been treated with both streptokinase and ultrasound. (A) The angiogram 30 minutes after the laser treatment shows that the vein is totally occluded peripheral to the thrombus. There is fluorescein in that part of the vein that is central to the thrombus, because of small veins that empty in the central part of the vein. (B) The angiogram 12 hours after the treatment shows that the vessel is open. Leakage from the retina of the fluorescein is noted around the place where the laser treatment had been performed.

open were considered as closed. Leakage of the fluorescein was noted around the laser treatment site.

In group 1 receiving streptokinase (50 000 $\mathrm{IU} / \mathrm{kg}$ ), all the vessels that had been occluded were open. In group 2, which had only been treated with streptokinase (25000 IU/kg), $4 / 19(21 \%)$ of the vessels were open, and in group 3, which was treated with streptokinase (25 $000 \mathrm{IU} / \mathrm{kg}$ ) and ultrasound, 14/22 (64\%) of the vessels were open (Fig 1).

We used Fisher's exact test to assess statistical significance. There is a statistical significant difference between groups 1 and 2 ( $p<0.0001$; two sided), between groups 1 and 3 ( $p=0.03$; two sided), and between groups 2 and 3 ( $p=0.011$; two sided).

\section{Discussion}

Thrombolytic treatment with streptokinase or tissue plasminogen activator of retinal vein occlusions in humans has been performed before with fairly good results. $.^{9-12} 24-26$ The thrombolytic treatment is not widely used today in retinal vein occlusion, because of severe side effects such as haemorrhage. If it were possible to lower the dose of the thrombolytic drug and thus lower the frequency of the side effects, and still maintain good thrombolytic effect by adding therapeutic ultrasound, it is probable that this treatment would be of greater clinical interest.

The results of this study suggest that it is possible to reduce the dose of streptokinase and still retain a good thrombolytic effect by adding ultrasound. It has previously been 
shown that streptokinase at a dose of 25000 $\mathrm{IU} / \mathrm{kg}$ in the rabbit is insufficient to dissolve an arterial thrombus in the ileofemoral artery, but when ultrasound was added transcutaneously, $59 \%$ of the thrombi were dissolved. ${ }^{27}$ In our study a dose of streptokinase of $50000 \mathrm{IU} / \mathrm{kg}$ dissolved $100 \%$ of the thrombi in the retinal veins. This shows that it is possible to lyse the experimental thrombi if the streptokinase dose is high enough. When the dose was halved to $25000 \mathrm{IU} / \mathrm{kg}$, the proportion of lysed thrombi fell to $21 \%$, showing that the lysis of thrombi is dose dependent. When adding pulsed ultrasound to the lower dose of streptokinase, we managed to lyse $64 \%$ of the thrombi, thus showing that pulsed ultrasound is an efficient adjuvant to streptokinase treatment.

In a previous work, ${ }^{21}$ we found an intensity "window" for in vitro experiments with ultrasound. The effect of streptokinase induced thrombolysis was more enhanced when combined with ultrasound of the intensity $1 \mathrm{~W} / \mathrm{cm}^{2}$ than with any other, therefore we chose that intensity for this study. The first two rabbits, which were excluded from the study, were given continuous ultrasound. However, these rabbits developed haemorrhage in the anterior chamber, and the intensity had to be lowered. This was achieved by changing to pulsed ultrasound with a $10 \%$ duty cycle, after which no more haemorrhages were seen. Since haemorrhage is a non-acceptable side effect, future studies should be made to find the most beneficial ultrasound intensity.

This study was supported by Synfrämjandets Forskningsfond Sweden, Carmen och Bertil Regnérs Stiftelse för Forskning inom Området Ogonsjukdomar Sweden, Elsa och Ola Ohlsson Fond för Ögonforskning Sweden, Malmöhus Läns Landsting Sweden, Svenska Sällskapet för Medicinsk Forskning Sweden, and The Swedish Heart Lung foundation. We would also like to thank Karin Arnér and Bjarne Madsen for technical assistance.

1 Hayreh SS, Rojas P, Podhajsky P, et al. Ocular neovascularization with retinal vein occlusion. Ophthalmology 1983;90:488-506.

2 Hansen LL, Hovener G, Mercks C, et al. [Isovolemic hemodilution in patients with retinal branch vein occlusion]. Fortschr Ophthalmol 1985;82:290-2.

3 Hansen LL, Danisevskis P, Arntz HR, et al. A randomised Hansen LL, Danisevskis P, Arntz HR, et al. A randomised
prospective study on treatment of central retinal vein prospective study on treatment of central retinal vein
occlusion by isovolaemic haemodilution and photocoagulaocclusion by isovolaemic haemodilution
tion. Br $\mathcal{\text { Ophthalmol }}$ 1985;69:108-16.

4 Hansen LL, Wiek J, Arntz R. [Randomized study of the effect of isovolemic hemodilution in retinal branch vein occlusion]. Fortschr Ophthalmol 1988;85:514-16.

5 Wiederholt $\mathrm{M}$, Leonhardt $\mathrm{H}$, Schmid Schonbein $\mathrm{H}$, et al. [Treatment of central retinal venous and arterial occlusion by isovolemic hemodilution (author's transl)]. Klin Monatsbl Augenheilkd 1980;177:157-64.

6 Poupard P, Eledjam JJ, Dupeyron G, et al. [ [Role of acute normovolemic hemodilution in treating retinal venous occlusions]. Ann Fr Anesth Reanim 1986;5:229-33.
7 Hansen LL, Wiek J, Schade M, et al. Effect and compatibility of isovolaemic haemodilution in the treatment of ischaemic and non-ischaemic central retinal vein occlusion. Ophthalmologica 1989;199:90-9.

8 Hansen LL, Wiek J, Wiederholt M. A randomised prospective study of treatment of non-ischaemic central retinal vein occlusion by isovolaemic haemodilution. $\mathrm{Br} \mathcal{F}$ Ophthalmol 1989;73:895-9.

9 Steinkamp GW, Hattenbach LO, Scharrer I, et al. [Frontloading $\mathrm{rt}$ PA thrombolytic therapy in central or venous branch occlusions of the retina]. Ophthalmologe 1994;91: $280-2$.

10 Kohner EM, Hamilton AM, Bulpitt CJ, et al. Streptokinase in the treatment of central retinal vein occlusion. A controlled trial. Trans Ophthalmol Soc UK 1974;94:599603.

11 Pettit JE, Kohner EM, Bulpit CJ, et al. Proceedings: Fibrinolytic therapy in central retinal vein occlusion. Thromb Diath Haemorrh 1975;34:569.

12 Kohner EM, Pettit JE, Hamilton AM, et al. Streptokinase in central retinal vein occlusion: a controlled clinical trial. BMF 1976;1:550-3.

13 McAllister IL, Constable IJ. Laser-induced chorioretinal venous anastomosis for treatment of nonischemic central retinal vein occlusion [see comments]. Arch Ophthalmol 1995;113:456-62.

14 Glacet Bernard A, Coscas G, Chabanel A, et al. A randomized, double-masked study on the treatment of retinal vein occlusion with troxerutin. Am f Ophthalmol 1994; 118:421-9.

15 Radnot M, Follmann P. Rheomacrodex (Dextran) in the treatment of the occlusion of the central retinal vein. Ann Ophthalmol 1969;1:58.

16 (FTT) Collaborative Group. Indications for fibrinolytic therapy in suspected acute myocardial infarction: collaborative overview of early mortality and major morbidity results from all randomised trials of more than 1000 patients. Fibrinolytic Therapy Trialists' (FTT) Collaborative Group [published erratum appears in Lancet 1994;343: 742] [see comments]. Lancet 1994;343:311-22.

17 Granger CB, Califf RM, Topol EJ. Thrombolytic therapy for acute myocardial infarction. A review [published erratum appears in Drugs 1993;45:894]. Drugs 1992;44:293-325.

18 Hamilton AM, Kohner EM, Rosen D, et al. Experimental retinal branch vein occlusion in rhesus monkeys. I. Clinical appearances. Br f Ophthalmol 1979;63:377-87.

19 Royster AJ, Nanda SK, Hatchell DL, et al. Photochemical initiation of thrombosis. Fluorescein angiographic, histologic, and ultrastructural alterations in the choroid, retinal pigment epithelium, and retina. Arch Ophthalmol 1988;106: 1608-14.

20 Nanda SK, Hatchell DL, Tiedeman JS, et al. A new method for vascular occlusion. Photochemical initiation of thrombosis. Arch Ophthalmol 1987;105:1121-4.

21 Nilsson AM, Odselius R, Roijer A, et al. Pro- and antifibrinolytic effects of ultrasound on streptokinase-induced thrombolysis. Ultrasound Med Biol 1995;21:833-40.

22 Olsson SB, Johansson B, Nilsson AM, et al. Enhancement of thrombolysis by ultrasound. Ultrasound Med Biol 1994;20: 375-82.

23 Oncel M, Peyman GA, Khoobehi B. Tissue plasminogen activator in the treatment of experimental retinal vein occlusion. Retina 1989;9:1-7.

24 Reim M, Bertram B, Wolf S. [Treatment trials of plasminogen activator (rt-PA) in central vein thrombosis of the retina]. Klin Wochenschr 1988;66(Suppl 12):143-9.

25 Elman MJ. Thrombolytic therapy for central retinal vein occlusion:results of a pilot study. Trans Am Ophthalmol Soc 1996;94:1984-6.

26 Kreutzer A, Brunner R, Schafer HJ, et al. [Thrombolytic therapy with recombinant tissue-type plasminogen activator in patients with branch or central vein occlusion of the retina.] Fortschr Ophthalmol 1988;85:511-13.

27 Luo H, Nishioka T, Fishbein MC, et al. Transcutaneous ultrasound augments lysis of arterial thrombi in vivo. Circulation 1996;94:775-8 